\title{
Influence of solidification rates and heat treatment on the mechanical performance and joinability of the cast aluminium alloy AISi10Mg
}

\author{
M. Neuser ${ }^{1}$ (1) $\cdot$ O. Grydin ${ }^{1} \cdot$ Y. Frolov $^{2} \cdot$ M. Schaper ${ }^{1}$
}

Received: 15 October 2021 / Accepted: 10 January 2022 / Published online: 23 January 2022

(c) The Author(s) 2022

\begin{abstract}
In modern vehicle chassis, multi-material design is implemented to apply the appropriate material for each functionality. In spaceframe technology, both sheet metal and continuous cast are joined to castings at the nodal points of the chassis. Since resistance spot welding is not an option when different materials are joined, research is focusing on mechanical joining methods for multi-material designs. To reduce weight and achieve the required strength, hardenable cast aluminium alloys of the AlSi-system are widely used. Thus, $85-90 \%$ of aluminium castings in the automotive industry are comprised of the AlSi-system. Due to the limited weldability, mechanical joining is a suitable process. For this application, various optimisation strategies are required to produce a crack-free joint, as the brittle character of the AlSi alloy poses a challenge. Thus, adapted castings with appropriate ductility are needed. Hence, in this study, the age-hardenable cast aluminium alloy AlSi10Mg is investigated regarding the correlation of the different thicknesses, the microstructural characteristics as well as the resulting mechanical properties. A variation of the thicknesses leads to different solidification rates, which in turn affect the microstructure formation and are decisive for the mechanical properties of the casting as well as the joinability. For the investigation, plates with thicknesses from 2.0 to $4.0 \mathrm{~mm}$, each differing by $0.5 \mathrm{~mm}$, are produced via sand casting. Hence, the overall aim is to evaluate the joinability of AlSi10Mg and derive conclusions concerning the microstructure and mechanical properties.
\end{abstract}

Keywords Cast aluminium alloy $\cdot$ Sand casting $\cdot$ Microstructure $\cdot$ Dendrite arm spacing $\cdot$ Mechanical joinability . Clinching

\section{Introduction}

Lightweight construction is one of the key topics in modern automotive engineering in order to increase sustainability by reducing mass. On the one hand, the lightweight construction can save resources and on the other hand, every kilogram saved reduces the emissions that a vehicle emits directly or indirectly [1]. Cast aluminium components contribute to the successful implementation of lightweight design in automotive. For example, cast components are required in the spaceframe design to absorb the pressure load at the load points and to allow optimum force guidance [2].

M. Neuser

neuser@1wk.upb.de

1 Department of Materials Science, Paderborn University, Paderborn, Germany

2 Department of Metal Forming, National Metallurgical Academy of Ukraine, Dnipro, Ukraine
In addition, aluminium castings are suitable due to their good mechanical properties, especially $\mathrm{AlSi}(\mathrm{Mg})$ alloys, which are characterised by their comparatively high strength [3]. These alloys are applied due to excellent castability, good surface quality and low melting temperature [4]. For this reason, the aluminium casting alloys of the AlSi-system are preferred in technical applications [5]. Before casting, a melt cleaning is necessary to extract the absorbed hydrogen from the melt, which is 20 times greater in the molten phase than in the solid phase [6]. During the solidification process, the hydrogen absorbed from the air combines to form molecular hydrogen and is accumulated in the interdendritic regions, which finally leads to gas pores [6]. Thus, the mechanical properties as well as the corrosion resistance are negatively influenced [7].

The weldability of such alloys is a challenge [3]. Therefore, the mechanical joining of AlSi-systems is a suitable option, but this is strongly dependent on the ductility of the material. Due to the brittle character of Al-Si alloys such as 
AlSi $10 \mathrm{Mg}$, it is usually not possible to join them mechanically without cracking with joining processes like clinching.

For the mechanical behaviour the alloying elements $\mathrm{Cu}$ or, as in AlSi10Mg, Si and $\mathrm{Mg}$ at the same time, are important, so that partially coherent and incoherent particles can form as a result of the precipitation hardening. Al-Si alloys are divided into three categories: hypoeutectic, eutectic and hypereutectic. The eutectic of this system is $12.5 \mathrm{wt} \%$ of $\mathrm{Si}$ [8]. In hypoeutectic and eutectic alloys, the microstructure consists of a needle-shaped silicon embedded in an aluminium matrix [9]. Furthermore, the shrinkage behaviour of the aluminium casting alloy is directly related to the silicon content. Especially in casting processes with faster solidification rates, such as permanent mould casting, or also in the casting of thin structures, as in the present investigation, there is a temperature dependence on the mass feeding. If the temperature gradient is too high, a too short mass feeding from already solidified areas to semi-solidified areas takes place during solidification. The temperature is already relatively low for a mass feed through the solidified silicon to occur. Therefore, a higher proportion of silicon must be added so that the mass feeding can continue to take place at higher solidification speeds between fully and semi-solidified structures. Therefore, aluminium alloys with a silicon content of $5-7 \mathrm{wt} \%$ are used for slower solidification and 7-9 wt $\%$ for higher solidification rates [10].

Such aspects as the solidification rate, the microstructure as well as the casting process influence the mechanical properties of castings [10]. A characteristic of these alloys is their brittle character, which is influenced by the formation of the eutectic structure. In the AlSi-system, the eutectic structure has a needle- and plate-like formation. By adding $\mathrm{Na}$ or $\mathrm{Sr}$, a modification of the eutectic structure can be achieved, whereby it is rounder and more finely dispersed [11]. However, when modifying the melt with refining agents, it should be noted that the microshrinkage increases. This is caused by a reduction in surface tension, a change in dendrite morphology, more inclusions and a change in melt flow [9]. Another important possibility to influence the microstructure is the solidification rate, which depends on the casting process [1]. The higher the solidification rate, the finer the eutectic structure in the $\alpha$-aluminium matrix [12]. In addition, the distance between the growing dendrites, so called dendrite arm spacing (DAS), decreases the higher the solidification rate is. A very fine microstructure can be achieved by very high solidification rates, which is similar to a $\mathrm{Na}$ or $\mathrm{Sr}$ modified microstructure [13]. However, such high solidification rates cannot be achieved in sand casting [12]. As an example of an unmodified AlSi10Mg alloy, a microstructure photograph is shown in Fig. 1. This shows the typical silicon needle embedded in an $\alpha$-aluminium matrix of an unmodified and slowly solidified cast aluminium alloy, which has been sand cast. The dendritic structures solidify first as a result of solidification, because aluminium has a low solid solubility, which leads to the dendrites being surrounded by a second phase, the $\alpha$-aluminium matrix [9].

The sand casting process is suitable for almost all aluminium casting alloys. For this application, a distinction is made between the lost mould process and the permanent mould process. The former is used as the process in this study [6]. Either greensand or dry sand is used as a moulding material. Greensand is characterised by the fact that it does not need to be combined with an additional binder system, as is the case with dry sand, for example. Moulding sand, which usually has to be compacted during mould production, not only serves as a moulding compound but also as a permeable material for casting gases and air. The choice of sand can also influence the solidification of the melt so that different types of moulding material have different heat capacities. Finally, there is an additional possibility to influence the mechanical properties of the casting [10].

Clinching is a mechanical joining process that is widely used in automotive engineering [14]. This process is suitable especially in cases where two different materials are to be joined [15]. In this process, two or more layers of material are joined together without inserting a joining element or pre-formed a pilot hole, which reduces the weight in comparison to other joining process. By means of a punch and a die, a joining point is set which represents a frictional and form-fitting joint. Especially the interlock and the residual bottom thickness of a clinch joint are the relevant indicators [16]. Clinch joints are often used in applications which do not require a high-strength joint. This includes, for example, chassis or engine covers as well as protective covers for the exhaust tract. Furthermore, parts of automotive seats as well as door structures are joined with this joining method. In
Fig. 1 Light microscopy (LM) image of the microstructure of hypoeutectic AlSi10Mg alloy

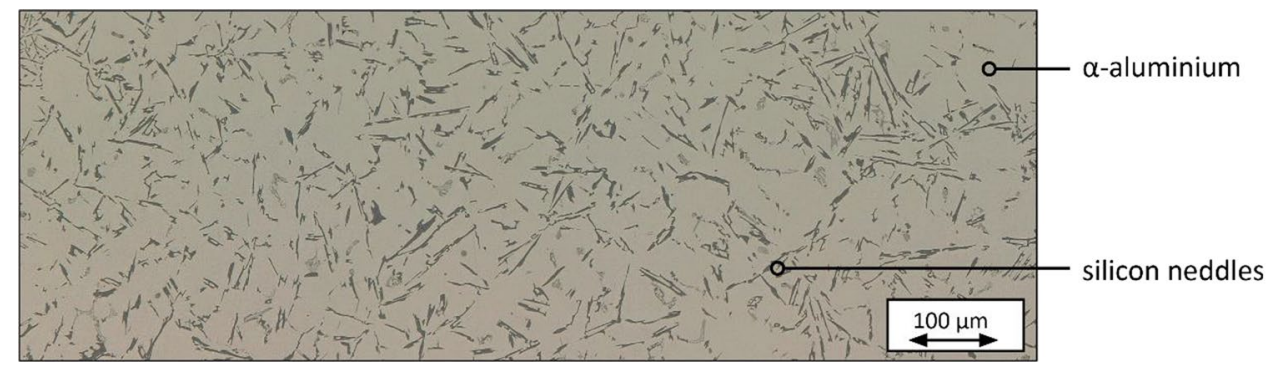


this way, the entire lightweight construction potential can be exploited, especially when using aluminium alloys, as the weight is not unnecessarily increased by a joining element [15].

\section{Materials and methods}

\subsection{Parts production}

The aluminium casting alloy $\mathrm{AlSi} 10 \mathrm{Mg}$ respectively EN AC-43000 was used in the study. This alloy was purchased from Trimet SE and is characterised by an excellent castability. Here, the AlSi10Mg is predestined to cast very thin structures, thinner than $3 \mathrm{~mm}$, in the sand casting process. Moreover, there is the possibility of increasing the strength by precipitation hardening. The precipitation hardening is given by the elements $\mathrm{Si}$ and $\mathrm{Mg}$. Due to a content of $9.1 \mathrm{wt} \% \mathrm{Si}$, the AlSi10Mg can be classified as a hypoeutectic alloy.

Moreover, the dual-phase steel HCT590x from Salzgitter Flachstahl GmbH was used on the punch side as part of the joining testing [17].

The chemical composition of AlSi10Mg was determined with the optical emission spectroscope Q4 Tasman from the company Bruker. These results are necessary for the later course of the study to be able to analyse the microstructure more comprehensively.

A part of the samples was precipitation-hardened before the various examinations. For this application, the samples were solution heat treated at a temperature of $525^{\circ} \mathrm{C}$ for $4 \mathrm{~h}$ and then quenched in water. Finally, the samples were artificially aged at $170{ }^{\circ} \mathrm{C}$ for $6 \mathrm{~h}$. All the temperatures are in accordance with the guideline W7 of GDA (Gesamtverband der Aluminiumindustrie, english General Association of the Aluminium Industry) [18].

The following investigations are carried out simultaneously on specimens in the as-cast state (F-state) and in the T6 state.

\subsection{Measurements of solidification rates}

Melting of the casting alloy was carried out in a resistance furnace. In the melting process, $2 \mathrm{~kg}$ of the alloy were superheated to a temperature of $720{ }^{\circ} \mathrm{C}$ in a graphite crucible coated with boron nitride. Before each casting, the melt was cleaned with the melt cleaning agent Degasal from Schäfer Metallurgie $\mathrm{GmbH}$. For this purpose, $10 \mathrm{~g}$ of Degasal were added to the melt and pressed down into the melt with a dipping bell. The reaction time was $4 \mathrm{~min}$. After removing the dipping bell, the slag on the melt was removed and cast immediately.
Two different metal models were used for moulding in the casting tests. On one hand, a five-stage plate (stepped plate), starting with a thickness of $2 \mathrm{~mm}$ up to $4 \mathrm{~mm}$, from which samples were taken for the mechanical and microstructure investigations. Each step has a dimension of $40.0 \mathrm{~mm} \times 80.0 \mathrm{~mm}$. On the other hand, a plate with a constant thickness of $2 \mathrm{~mm}$ and the dimensions $240.0 \mathrm{~mm} \times 120.0 \mathrm{~mm}$ was used, from which specimens were taken for the clinching tests according to the DVS guideline [16].

In addition, during the casting tests with the step plate, the solidification temperatures were recorded for each step using type $\mathrm{K}$ thermocouples and a frequency of $100 \mathrm{~Hz}$. As a measuring amplifier, the device Gantner Q.brixx XL A107 was used as well as using the Gantner GI.bench software to record the data. For this purpose, the thermocouples were formed into the sand and positioned in the middle of each section. This measuring method allows determining the solidification rates for the plate thickness since the thickness of a cast component significantly influences the solidification and thus also the microstructure and the associated joinability. The experimental setup of the sand casting process and the measurement technique used are shown in Fig. 2.

\subsection{Metallographic investigations}

For the metallographic investigations, the specimens were embedded in the 2-component system CEM1000 blue from Cloeren Technology, with a mixing ratio of 1 resin to 2 powder. The samples were then ground with $\mathrm{SiC}$ paper to a grit size of 4000 and polished for $18 \mathrm{~h}$ with an automatic ultrasonic polishing machine. For this application, a Silica suspension from Cloeren Technology was used that contains

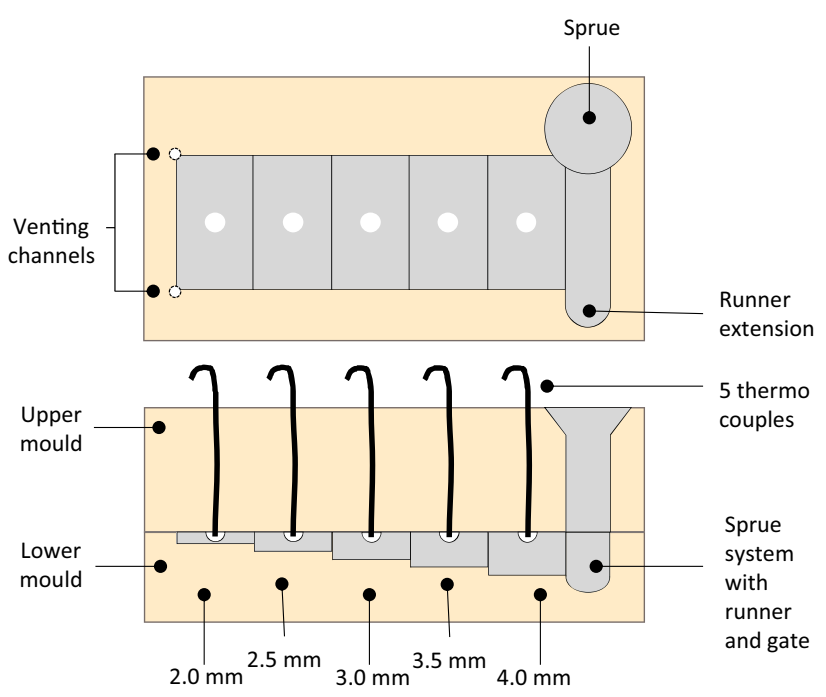

Fig. 2 Sand casting mould and the experimental setup for measurement of the solidification curves 
particles with an average size of $50 \mu \mathrm{m}$ and a $\mathrm{pH}$ value of 9-9.5. This causes a slight etching of the sample surface and thus slightly highlights the dendrites. For light microscopy (LM) and DAS measurement, the Keyence VHX5000 digital microscope was used.

The secondary dendrite arm spacing (DAS) is an essential parameter for evaluating the solidification rate. The faster solidification occurs in casting, the smaller the resulting dendrites spacing. The DAS is calculated as the quotient of the length of a dendrite stem and the number of dendrites as in Eq. 1 shown. This method was applied according to the guideline BDG P220 [19]. At least 10 dendrite stems with a minimum number of five dendrites were measured. Furthermore, a minimum distance of $0.5 \mathrm{~mm}$ from the edge of the specimen should be maintained.

$D A S=\frac{x}{(m-1)}$

where $x=$ length of the dendrite stem, $m=$ number of dendrites.

\subsection{Mechanical testing}

Tensile specimens were taken from the cast stepped plate for the mechanical tests as well as specimens for the hardness test.

The tensile tests were carried out in accordance with DIN EN ISO 6892-1 on the MTS 858 Table Top tensile testing machine. For this application, a miniature flat tensile specimen was used, with the thickness of the specimen corresponding to the respective plate step. The tensile specimens have a length of $26 \mathrm{~mm}$ and a width of $7 \mathrm{~mm}$. In the tapered measuring range, the specimens are $3 \mathrm{~mm}$ wide and have a radius of $2 \mathrm{~mm}$.

The hardness test was carried out according to Brinell in conformity with DIN EN ISO 6506-1 at all thickness levels. For this purpose, the samples were grinded with sandpaper with a grit of 4000 before the measurement. The test load was $62.5 \mathrm{kp}$ and the impactor was a tungsten carbide ball with a diameter of $2.5 \mathrm{~mm}$. According to the standard, a holding time of the force of $10-15 \mathrm{~s}$ was observed. The Frankoskop hardness tester was used for the measurement.

\subsection{Joining of clinching specimen}

The cast aluminium plates and the HCT590x blanks with a thickness of $1.5 \mathrm{~mm}$ were joined using the single-stage clinching process. Here, the steel sheet was used on the punch side and the casting on the die side. The joining points were set on the MC 4.8 system from the company Tox. The punch model A48105 and the die model BB8008 were used for this application. Table 1 shows the values for a suitable clinch joint. The mentioned values are to be considered
Table 1 Values for a suitable clinch joint according to DVS-guideline [16]

\begin{tabular}{lccc}
\hline Specific name & $\begin{array}{l}\text { Min. } \\
\text { single } \\
\text { value }\end{array}$ & $\begin{array}{l}\text { Min. } \\
\text { mean } \\
\text { value }\end{array}$ \\
\hline $\begin{array}{l}\text { Bottom thickness punch side } \\
\text { in mm }\end{array}$ & $\mathrm{t}_{\mathrm{bs}}$ & 0.20 & - \\
$\begin{array}{l}\text { bottom thickness die side } \\
\text { in mm }\end{array}$ & $\mathrm{t}_{\mathrm{bm}}$ & 0.20 & - \\
$\begin{array}{l}\text { Neck thickness (left/right) } \\
\text { in mm }\end{array}$ & $\mathrm{t}_{\mathrm{nl}, \mathrm{r}}$ & 0.20 & 0.25 \\
$\begin{array}{l}\text { Interlock } \\
\text { in mm }\end{array}$ & $\mathrm{f}_{\mathrm{hl}, \mathrm{r}}$ & 0.10 & 0.16 \\
\hline
\end{tabular}

as minimum values and should not be dropped under to achieve a suitable clinch joint. Furthermore, for interlock and neck thickness it is important that the average of the two measured values, once per side, does not undercut a mean value of $0.25 \mathrm{~mm}$ (neck thickness) and $0.16 \mathrm{~mm}$ (interlock) respectively.

\section{Results and discussion}

\subsection{Chemical composition}

The chemical composition of AlSi10Mg and HCT590x, which was used as a joining sheet in further investigation, is shown in Table 2. Samples analysed of the AlSi10Mg used here have the required chemical composition according to the standard DIN EN 1706.

In addition, the elements $\mathrm{Na}$ and $\mathrm{Sr}$ are listed in Table 2. Due to the very low content of $0.0001 \mathrm{wt} \%$-Sr and $0.0002 \mathrm{wt} \%-\mathrm{Na}$, it is possible to exclude a modification effect. For Sr, a content of approx. $0.02 \mathrm{wt} \%$ and for Na, a content of $0.01 \mathrm{wt} \%$ is considered to modify the eutectic [20].

\subsection{Solidification curve and cooling rate}

For the evaluation of the mechanical characteristics and the subsequent joining examination, it is essential to know the solidification condition of the AlSi10Mg manufactured in the sand casting process. Figure 3 shows the characteristic solidification curves for the five different plate thicknesses. It can be seen for this application that the thicker the plate, the higher the respective curve. The $2 \mathrm{~mm}$ thick plate, for example, solidifies within $4.3 \mathrm{~s}$, while the $4 \mathrm{~mm}$ level requires $22.3 \mathrm{~s}$.

The solidification rate of the individual stages was determined based on the cooling curve analysis method (CCA method) [21]. Figure 4 shows the first derivation of the 
Table 2 Chemical composition of cast aluminium alloy AlSi10Mg and the steel sheet HCT590x

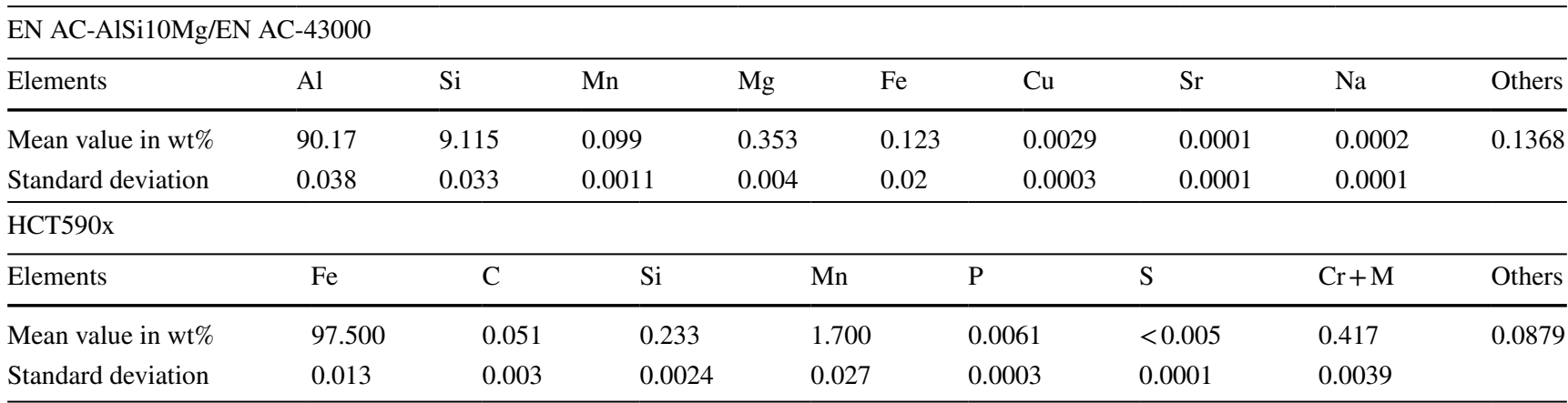

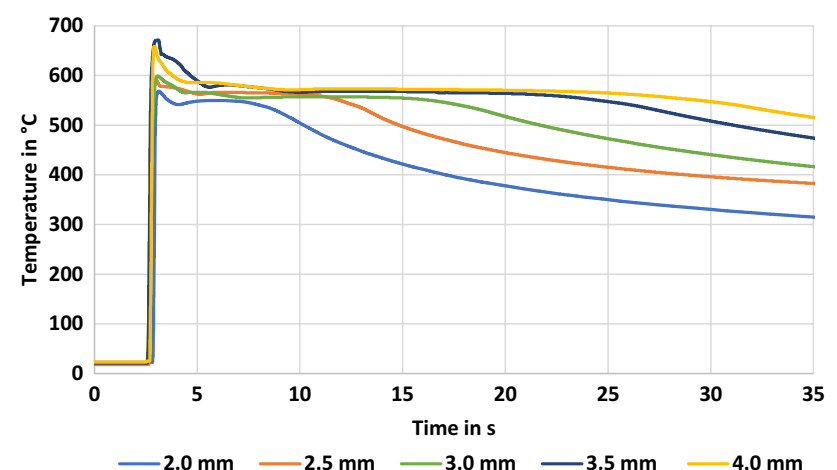

Fig. 3 Solidification curves of the five aluminium castings with different thicknesses

solidification curve of the $2 \mathrm{~mm}$ thick step. Two points are striking for this method. At the first point, the gradient rises and crosses the $\mathrm{X}$-axis, which represents the liquidus point of solidification according to the CCA method. Up to this point, only the melt phase is present. The melt cools at a rate of up to $322 \mathrm{~K} / \mathrm{s}$ until the phase boundary of the $\alpha$-region is reached, resulting in a kink point in the solidification curve (see left red vertical line in Fig. 4). The point in time at which the eutectic line in the phase diagram is reached corresponds to the time at which the solidification curve crosses the left red vertical line and the derivative is almost zero along the stopping line (solidification range). As soon as the gradient falls sharply and reaches a value other than zero, the solidification of the component is complete. This is the solidus point, which is the second point (see right red vertical line).

Using Eq. (2), the quotient is formed by knowing the temperature delta and the solidification time delta, which in this case gives the solidification rate SR [22]:

$S R=\frac{\Delta T_{\text {Solidus } \rightarrow \text { Liquidus }}}{\Delta t_{\text {Solidus } \rightarrow \text { Liquidus }}}$

In Table 3, the solidification rates SR of the respective stages are listed. For this application, the solidification rates range between $4.42 \mathrm{~K} / \mathrm{s}$ in the $2 \mathrm{~mm}$ thick stage and $1.89 \mathrm{~K} / \mathrm{S}$ in the $4 \mathrm{~mm}$ thick stage. There is almost a linear relationship between the plate thickness and the solidification rate apart from the $2 \mathrm{~mm}$, which solidified very fast. In the very small cavity of the $2 \mathrm{~mm}$ thick stage, the heat is dissipated

Table 3 Solidification rates determined via thermo-couples

\begin{tabular}{llllll}
\hline Stage thickness in mm & 2 & 2.5 & 3.0 & 3.5 & 4.0 \\
Solidification rate in K/s & 4.42 & 3.11 & 2.81 & 2.48 & 1.89 \\
\hline
\end{tabular}

Fig. 4 Solidification rate using the example of the $2 \mathrm{~mm}$ thickness

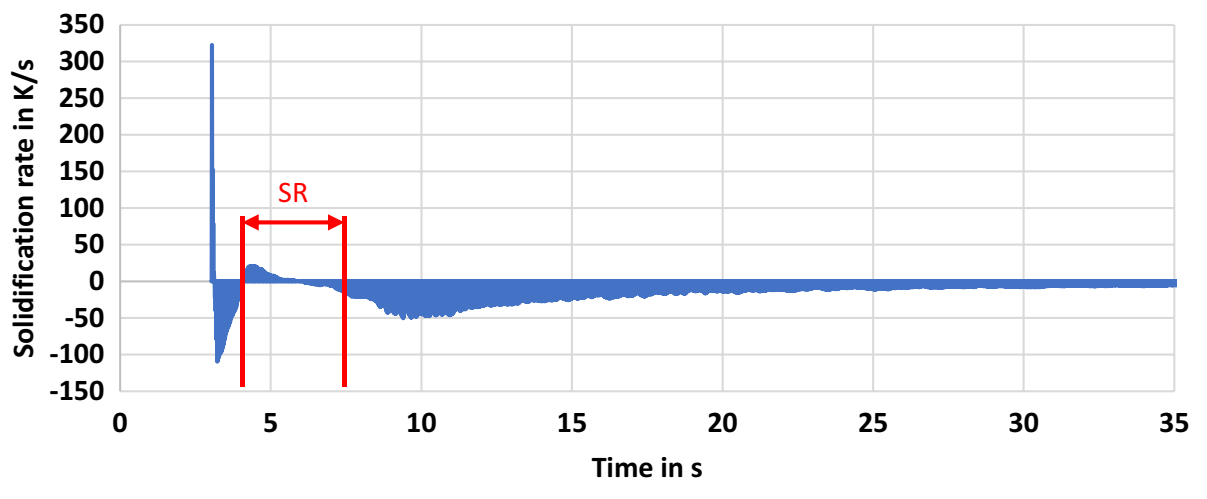

1. derivation of $2 \mathrm{~mm}$ solidification curve 
very fast and even the 2.5 and $3 \mathrm{~mm}$ solidify relatively fast. Furthermore, although the cross-section area of the $2 \mathrm{~mm}$ stage is $50 \%$ smaller than the $4 \mathrm{~mm}$ stage, parameters such as the flow direction and length are of decisive importance, as is the sand compression of the individual areas.

\subsection{Secondary dendrite arm spacing}

Figure 5 shows five microscopic images from the crosssectional areas of the 2 to $4 \mathrm{~mm}$ thick plates. All images show the typical flake-like structure of a non-refined cast aluminium alloy that has solidified relatively slowly. In this case, the eutectic silicon is precipitated in plate form and surrounded by an $\alpha$-aluminium matrix, with both phases separated from each other. During the solidification of the melt, the Si crystals are broken from the solidification front and this needle- and plate-shaped Si eutectic is formed. During this solidification process, the $\mathrm{Si}$ crystals formed drift away and grow into the microstructures shown here. The result is an $\alpha$-aluminium matrix with alternating formed eutectic [11].

Furthermore, the comparison of the five images clearly shows that the thicker the cast plate, the coarser the eutectic structure. In addition, the aluminium dendrites formed in the aluminium cast plates of different thicknesses are recognisable. Again, the same relationship exists, the thinner the plate the lower the DAS. The evaluation of the measured DAS for each plate level can be seen in Table 4. At the smallest plate thickness of $2 \mathrm{~mm}$, a DAS of $15.8 \mu \mathrm{m}$ was measured. In each further step, the DAS increases by 3 or $4 \mu \mathrm{m}$ until a DAS of
Table 4 Results of the DAS measurement for the different plate thicknesses

\begin{tabular}{llllll}
\hline Stage thickness in mm & 2.0 & 2.5 & 3.0 & 3.5 & 4.0 \\
DAS in $\mu \mathrm{m}$ & 15.8 & 18.4 & 22.6 & 26.5 & 29.8 \\
Standard deviation & 1.9 & 1.7 & 1.7 & 2.4 & 1.6 \\
\hline
\end{tabular}

$29.8 \mu \mathrm{m}$ could be measured at $4 \mathrm{~mm}$ plate thickness. From this, it can be deduced that the thicker a plate step is, the slower the respective solidification of the cast component takes place. This in turn means that a faster solidification in the $2 \mathrm{~mm}$ thick stages results in a finer cast structure than in the $4 \mathrm{~mm}$ stage, for example. Furthermore, the mechanical properties correlate directly with the DAS. The following applies here: The smaller the DAS, the better the mechanical properties [11]. See here also Table 5. However, it should be noted that in the literature it is assumed that sand casting is usually only carried out up to a minimum thickness of $4 \mathrm{~mm}$, but as shown here it can also be carried out at a thickness of $2 \mathrm{~mm}$ [10].

Figure 6 compares the results of the solidification rate and the DAS measurement. For this application, the linear relationship between the solidification rate and the DAS in relation to the plate thickness is noticeable. The faster the solidification and the thicker the respective step, the greater the DAS, i.e. the common inversely proportional relationship.
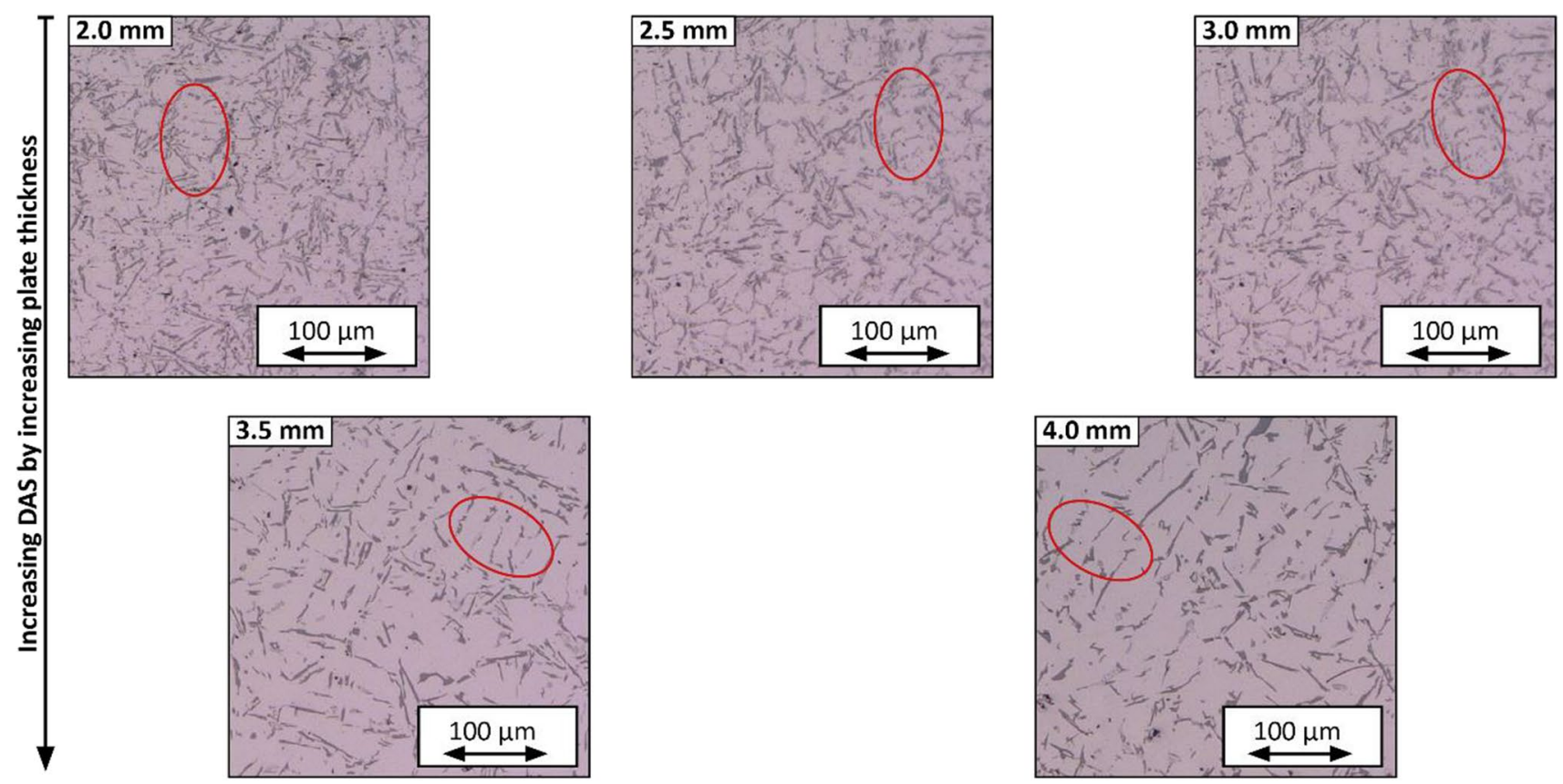

Fig. 5 Microscope images of AlSi10Mg with a thickness of $2 \mathrm{~mm}$ up to $4 \mathrm{~mm}$, some dendrites are marked in red 
Table 5 Mechanical properties of AlSi10Mg processed by sand casting

\begin{tabular}{llllll}
\hline Thickness in mm & 2.0 & 2.5 & 3.0 & 3.5 & 4.0 \\
Hardness in HBW & $74 \pm 0$ & $72 \pm 2$ & $70.6 \pm 2$ & $70.4 \pm 1$ & $68.6 \pm 2$ \\
Hardness in HBW after heat treatment & $106 \pm 1$ & $102 \pm 3$ & $106.4 \pm 2$ & $108.4 \pm 3$ & $108.4 \pm 2$ \\
Tensile strength in MPa & $223 \pm 33$ & $189 \pm 11$ & $179 \pm 18$ & $163 \pm 11$ & $169 \pm 14$ \\
Tensile strength in MPA after heat treatment & $286 \pm 23$ & $286 \pm 29$ & $287 \pm 42$ & $291 \pm 23$ & $270 \pm 48$ \\
Elongation at fracture in \% & 4.1 & 3.9 & 3.1 & 2.7 & 2.5 \\
Elongation at fracture in \% after heat treatment & 8.2 & 6.0 & 4.1 & 3.3 & 2.3 \\
\hline
\end{tabular}

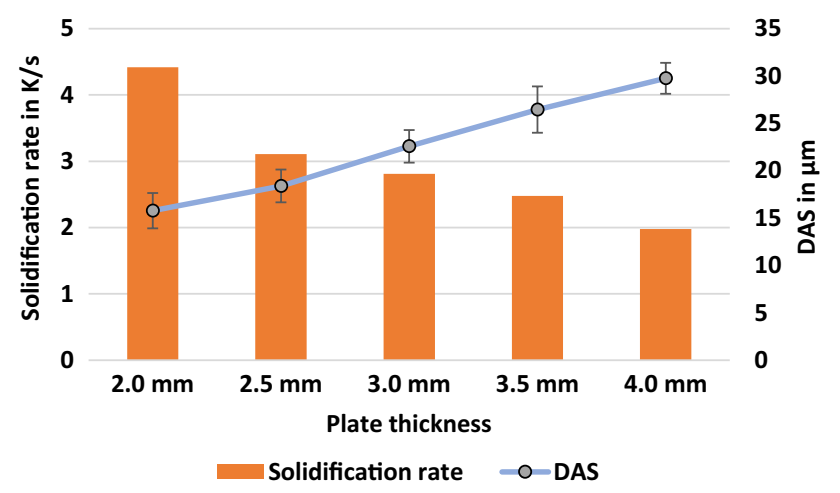

Fig. 6 Correlation between solidification rate, DAS and thickness

\subsection{Mechanical properties}

The solidification rate also has a direct influence on the mechanical properties of the cast components. The faster the solidification, the better the mechanical properties. Table 5 shows the various measured mechanical properties of the respective plate thicknesses. The expected increase in the characteristic values for the samples that are not heat-treated is visible. The hardness is $8 \%$ higher in the $2 \mathrm{~mm}$ step than in the $4 \mathrm{~mm}$ thick step. The presented hardness values differ due to the changed microstructure influenced by the solidification rate, whereby the values given in Table 5 are exemplary for the conducted measurements and can be regarded as reproducible. Similar investigations were also carried out on hypoeutectic AlSi9 [23]. Although the hardness values are at a lower level, these also show a decreasing hardness curve with increasing thickness. The fast solidification conditions are particularly evident in the tensile strength. In the $2 \mathrm{~mm}$ thick specimens, this is $25 \%$ higher than in the $4 \mathrm{~mm}$ thick specimens. With regard to the clinching of cast aluminium alloys, elongation of fracture is another decisive characteristic value. Thus, a solidification rate of $4.42 \mathrm{~K} / \mathrm{s}$ in the $2 \mathrm{~mm}$ thick specimen increases the elongation of fracture by $39 \%$ compared to the $4 \mathrm{~mm}$ specimen.

A comparison of the mechanical properties of the nonprecipitation-hardened samples with the precipitationhardened samples shows that all mechanical properties have increased. However, it is noteworthy that the tensile strength and hardness have almost equalised across all stages, regardless of the respective solidification rate. Only the elongation at fracture still shows a marked upward trend. The elongation at fracture was almost doubled During the transition from $4 \mathrm{~mm}$ thick stage to $2 \mathrm{~mm}$ thick stage.

\subsection{Analysis of mechanical joinability}

In the last part of the analysis, samplings were produced consisting of HCT590X $(1.5 \mathrm{~mm})$ on the punch side and 2 and $3 \mathrm{~mm}$ of AlSi10Mg on the die side. The joined samples are shown as cross-sections in Fig. 7.

It is noticeable for this application that sample (a) complies with the required limit values for a suitable joint. However, macro cracks are visible in the ring channel. Furthermore, in the precipitation-hardened sample (c), the interlock formation is greater and no cracks occur. Although the residual bottom thickness in (c) is lower in the punchside sheet than in (a), the higher hardness of the AlSi10Mg allowed the punch-side sheet to flow better into the interlock. If samples (b) and (d) with a thickness of $3 \mathrm{~mm}$ are used for comparison, it is noticeable that the characteristic values for the interlock (see Table 1) cannot be met. However, in contrast, to sample (b), the limit value for the neck thickness can be complied with on both sides in sample (d). The neck thickness in sample (b) is only $0.150 \mathrm{~mm}$ on the left side and thus undercuts the limit values from the second column of Table 1. Also, the mean value of the neck thickness (left/ right) is with $0.191 \mathrm{~mm}$ below the given limit value (see Table 1, third column). Furthermore, when joining the $3 \mathrm{~mm}$ specimen in as-cast state (b), it is noticeable that a crack developed up to the edge of the specimen.

To further assess the joinability of AlSi10Mg, Fig. 8 shows the locking heads for the same parameters as in Fig. 7. Although samples (A) and (C) have cracks in the ring channel of the closing head, they are very small. In comparison, the $3 \mathrm{~mm}$ thick sample (D) also has cracks that are larger due to the lower elongation at fracture. Specimen (B) shows a crack that extends to the edge of the specimen. This is due to the fact that the untreated sample (B) has a lower elongation at fracture in comparison to the precipitation-hardened sample (D). During precipitation hardening of sample (D), 


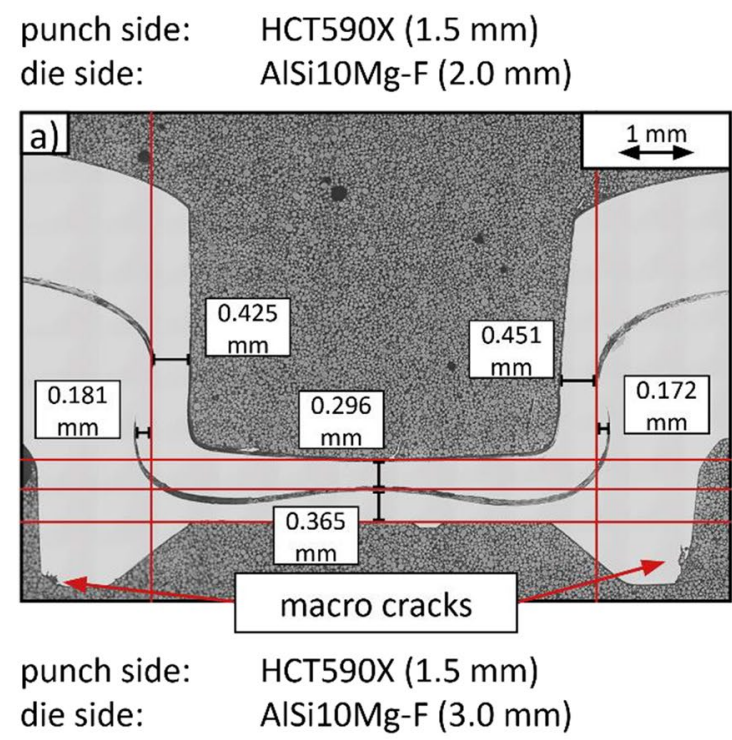

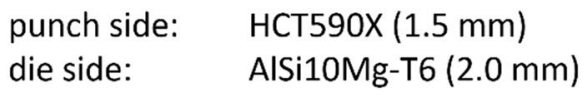

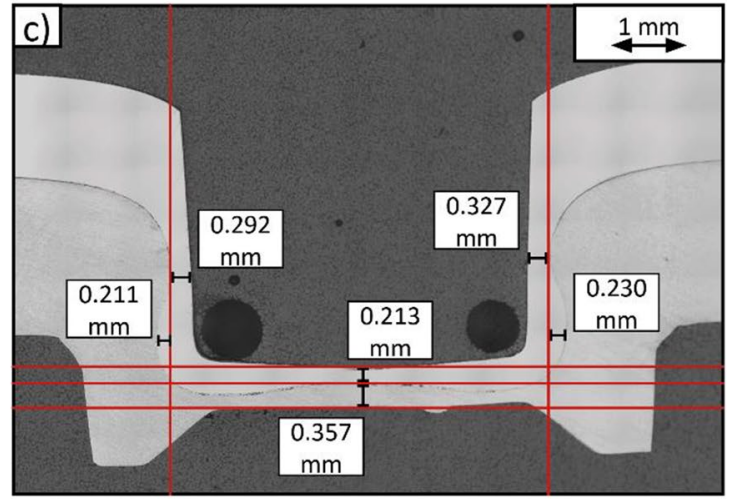

$\begin{array}{ll}\text { punch side: } & \text { HCT590X }(1.5 \mathrm{~mm}) \\ \text { die side: } & \text { AlSi10Mg-T6 }(3.0 \mathrm{~mm})\end{array}$

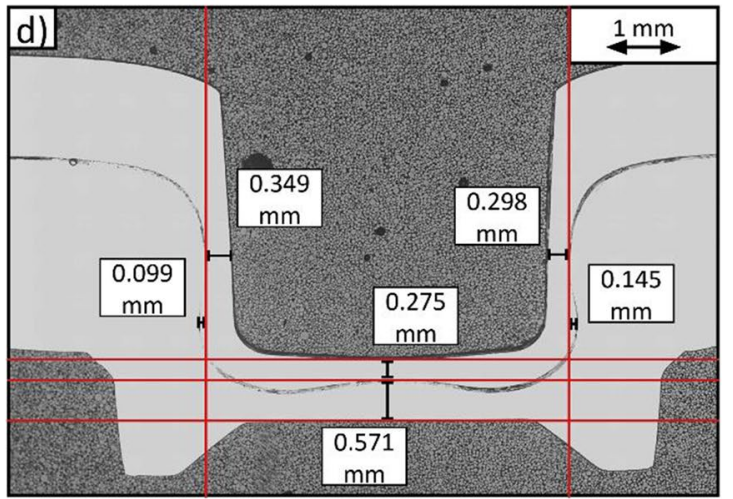

Fig. 7 Samplings of the clinched specimens, $\mathbf{a}$ and $\mathbf{b}$ with AlSi10Mg in as-cast condition at the die side, $\mathbf{c}$ and $\mathbf{d}$ with AlSi10Mg in T6-condition at the die side

diffusion takes place, which causes segregations to dissolve. The solidification rate, the DAS and the associated elongation at fracture are too low and thus do not allow a loadbearing joint.

The precipitation-hardened specimens generally show significantly improved joinability compared to the original cast state. In particular, the good joinability of the $2 \mathrm{~mm}$ thick specimen stands out. This means that in this context a solidification rate of $4.42 \mathrm{~K} / \mathrm{s}$ must be achieved, which is followed by a corresponding DAS and a fine microstructure is achieved. Accordingly, the elongation at fracture is increased to such an extent that a clinch joint can be produced. Thus, this is a promising approach to improve joinability. This significantly reduces the formation of cracks in the closing head of the joint, and the cracks that continue to occur are much smaller.

\section{Conclusions}

Within the scope of this study, the aluminium casting alloy AlSi10Mg was processed using the sand casting process and was subsequently characterised using various methods. The following conclusions can be drawn from the microscopic and mechanical analyses as well as from the joining evaluation:

- Within the study, an almost linear dependency between the secondary dendrite arm spacing (DAS) and solidification rate was found. The higher the solidification rate, the smaller the DAS. As a result, the highest mechanical characteristic properties were achieved in the thinnest $2 \mathrm{~mm}$ thick specimens as expected.

- Due to the finer microstructure, the $2 \mathrm{~mm}$ thick cast aluminium plates are particularly suitable as the material on the die side with a DAS of $15.8 \mu \mathrm{m}$.

- However, it has to be noted for this application that small cracks are visible in the closing head. The $3 \mathrm{~mm}$ 


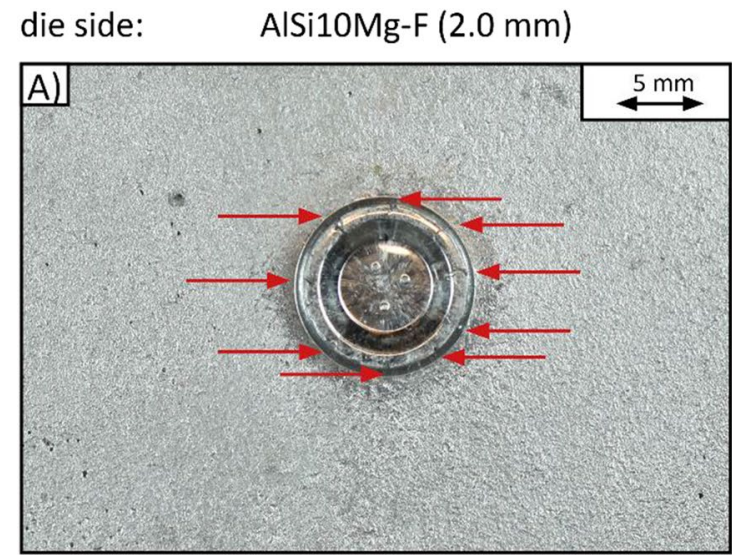

die side: $\quad$ AlSi10Mg-F $(3.0 \mathrm{~mm})$

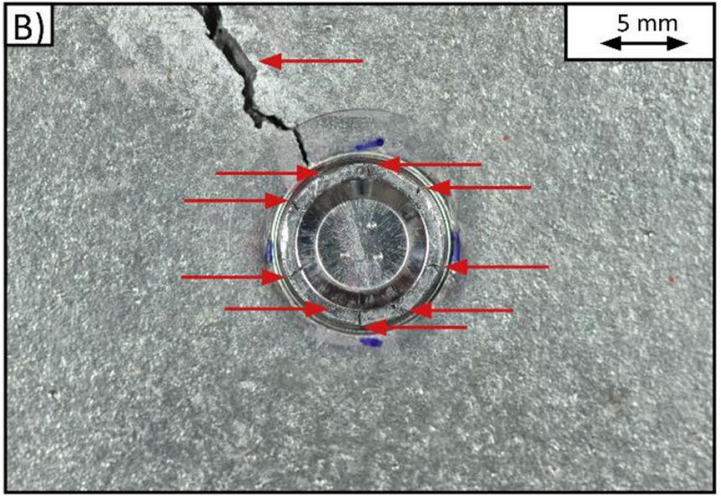

die side: $\quad$ AlSi10Mg-T6 $(2.0 \mathrm{~mm})$

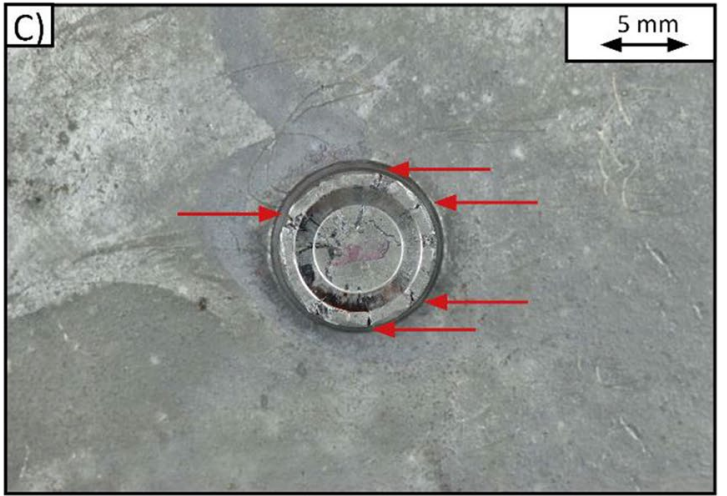

die side: $\quad$ AlSi10Mg-T6 $(3.0 \mathrm{~mm})$

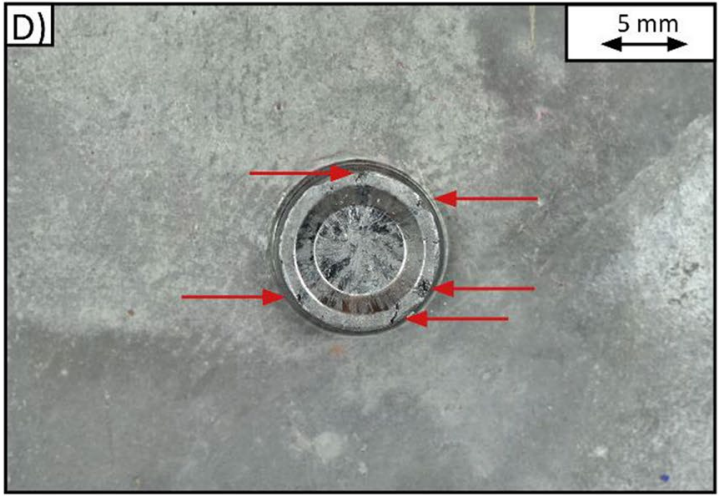

Fig. 8 Closing heads of samplings, $\mathbf{A}$ and $\mathbf{B}$ with AlSi10Mg in as-cast condition at the die side, $\mathbf{C}$ and $\mathbf{D}$ with AlSi10Mg in T6-condition at the die side, red arrows show cracks

thick samples show that the solidification rate and DAS achieved for this utilisation represent a limit value for joining, especially in the as-cast state.

- The heat treatment has a positive influence on the mechanical performance as well as on the joinability of castings.

- The joining of as-cast AlSi10Mg is not practicable without any further increase of the solidification rate, especially at a thickness of $3 \mathrm{~mm}$ and more.

Following investigations of joinability will include these two aspects:

- The modification element $\mathrm{Na}$ will be used to modify the eutectic into a finer and lamellar structure which increases the mechanical properties, especially the elongation at fracture.

- Testing of different ageing temperatures to be able to analyse the influence on the microstructure and the subsequent structure.
Acknowledgements The authors thank the German Research Foundation for their organizational and financial support. Furthermore, the authors would like to take this opportunity to thank Mr. Max Böhnke, research assistant at the Laboratory for material and joining technology, Paderborn University, and Mr. Jan Tobias Krüger and Mr. Martin Lauth, chair of Materials Science at the Paderborn University, Mr. Moritz Klöckner as well as Mr. Jonathan Hartmann for their support in preparation and conduction of casting trials.

Funding Open Access funding enabled and organized by Projekt DEAL. This research was funded by the Deutsche Forschungsgemeinschaft (DFG, German Research Foundation)-TRR 285-Project-ID 418701707.

Open Access This article is licensed under a Creative Commons Attribution 4.0 International License, which permits use, sharing, adaptation, distribution and reproduction in any medium or format, as long as you give appropriate credit to the original author(s) and the source, provide a link to the Creative Commons licence, and indicate if changes were made. The images or other third party material in this article are included in the article's Creative Commons licence, unless indicated otherwise in a credit line to the material. If material is not included in the article's Creative Commons licence and your intended use is not permitted by statutory regulation or exceeds the permitted use, you will 
need to obtain permission directly from the copyright holder. To view a copy of this licence, visit http://creativecommons.org/licenses/by/4.0/.

\section{References}

1. Friedrich HE (ed) (2017) Leichtbau in der Fahrzeugtechnik. Springer Fachmedien Wiesbaden, Wiesbaden

2. Mallick PK (2011) Materials, design and manufacturing for lightweight vehicles. Woodhead Publishing in Materials, CRC Press, Boca Raton

3. Machuta J, Nová I, Kejzlar P (2017) Structure and mechanical properties of aluminium alloys AlSi10 and AlSi5Mg. Manuf Technol 17(5):772-777. https://doi.org/10.21062/ujep/x.2017/a/ 1213-2489/MT/17/5/772

4. Polmear I, St. John D, Ne J, Qian M (2017) Light alloys. From traditional alloys to nanocrystals, 5th edn. Elsevier Science and Technology, Oxford

5. Glazoff MV (2019) Casting aluminum alloys, 2nd edn. Butterworth-Heinemann

6. Lumley RN (2018) Fundamentals of aluminium metallurgy. Production, processing and applications. Woodhead Publishing series in metals and surface engineering. Woodhead Publishing, Cambridge

7. Davis JR (ed) (2007) Aluminum and aluminum alloys, ASM specialty handbook, 6th edn. ASM International, Materials Park

8. Hatch JE (1984) Aluminum. Properties and physical metallurgy. American Society for Metals, Metals Park

9. Stefanescu DM, Ruxanda R (2004) Solidification structure of aluminum alloys ASM handbook vol. 9-metallography and microstructures. pp S107-S115

10. Kaufman JG, Rooy EL (2004) Aluminum alloy castings. Properties, processes, and applications. ASM International, Materials Park

11. Fredriksson H, Åkerlind U (2010) Materials processing during casting. Wiley, Chichester and Hoboken

12. Neuser M, Grydin O, Andreiev A, Schaper M (2021) Effect of solidification rates at sand casting on the mechanical joinability of a cast aluminium alloy. Metals 11(8):1304. https://doi.org/10. 3390/met11081304

13. Fredriksson H, Åkerlind U (2012) Solidification and crystallization processing in metals and alloys. Wiley, Chichester
14. Meschut G, Janzen V, Olfermann T (2014) Innovative and highly productive joining technologies for multi-material lightweight car body structures. J Mater Eng Perform 23(5):1515-1523. https:// doi.org/10.1007/s11665-014-0962-3

15. Mucha J (2017) Clinching technology in the automotive industry. Arch Autom Eng Arch Motor. https://doi.org/10.14669/AM.VOL. 76.ART4

16. DVS, EFB (2002) Merkblatt Clinchen (3420). DVS Media GmbH, Düsseldorf

17. Salzgitter Flachstahl (2017) HCT590X+Z. Mehrphasenstähle zum Kaltumformen-Dualphasenstähle. https://www.salzgitter-flach stahl.de/fileadmin/footage/MEDIA/gesellschaften/szfg/informatio nsmaterial/produktinformationen/feuerverzinkte_produkte/deu/ hct590x.pdf

18. Gesamtverband der Aluminiumindustrie (2007) Wärmebehandlung von Aluminium-Legierungen. Merkblatt W7. Merkblatt/ Aluminium-Zentrale W, Bd 7. GDA, Düsseldorf

19. BDG-Bundesverband der Deutschen Gießerei-Industrie (2011) P220-Bestimmung des Dendritenarmabstandes für Gussstücke aus Aluminium-Gusslegierungen. VDG, Düsseldorf

20. Ebhota WS, Jen T-C (2017) Effects of modification techniques on mechanical properties of Al-Si cast alloys. In: Sivasankaran S (ed) Aluminium alloys-recent trends in processing, characterization, mechanical behavior and applications. InTech, London

21. Emadi D, Whiting LV, Nafisi S, Ghomashchi R (2005) Applications of thermal analysis in quality control of solidification processes. J Therm Anal Calorim 81(1):235-242. https://doi.org/10. 1007/s10973-005-0772-9

22. Vandersluis E, Ravindran C (2019) Influence of solidification rate on the microstructure, mechanical properties, and thermal conductivity of cast A319 Al alloy. J Mater Sci 54(5):4325-4339. https:// doi.org/10.1007/s10853-018-3109-3

23. Neuser M, Kappe F, Busch M, Grydin O, Bobbert M, Schaper M, Meschut G, Hausotte T (2021) Joining suitability of cast aluminium for self-piercing riveting. IOP Conf Ser Mater Sci Eng 1157(1):12005. https://doi.org/10.1088/1757-899X/1157/1/ 012005

Publisher's Note Springer Nature remains neutral with regard to jurisdictional claims in published maps and institutional affiliations. 